\title{
Barriers to Implementation Sustainable Cement Manufacturing in Kuwait
}

\author{
Shaikha AlSanad ${ }^{1}$
}

\begin{abstract}
The concept of the sustainability has progressively become vital to business practice and research over the past decades because of rapid depletion of corporate social responsibility and disquiets over affluence inequality and natural resources. Cement, which is the key element of concrete, considered, as is the most, consumed material after water and this industry revealed one of the as most controversial industries due to its significant environmental impacts The cement industries are facing challenges to implement sustainable manufacturing into their products and processes. Thus, it is vital to evaluate the sustainable manufacturing in the cement industry. This paper is part of ongoing research aimed to identify and assess the extent of the utilization of efficient practice in the process of cement production in Kuwait and in turn produce new practice guidelines. Thus, the paper intends to address the challenge and barriers the sustainable manufacturing supposed to be suitable to the cement industry from the perspectives of the stakeholders. Consequently, research data was collected through a semi structure questionnaire survey of randomly selected professionals in cement factory in Kuwait. The results demonstration that vital barriers to sustainable cement factory such as Lack of environmental awareness by the industry, political decision makers, and clients, lack of strategy to promote sustainable construction, Inadequate regulation support, and Shortage of local environmental regulations
\end{abstract}

Keywords: cement industry, sustainability, sustainable manufacturing, sustainable development

\section{Introduction}

The term sustainability, which increasingly refers to an integration of social, environmental, and economic responsibilities, has begun to appear in the literature of business disciplines such as management and operations. In addition, companies are beginning to rapidly adopt the term sustainability. (Arbačiauskas, V.Staniškis, 2009). Globally, the sustainable development is a significant issue, it involves considering environmental sustainability according to social and economic constraints. Moreover, this concept has motivated numerous initiatives, national and international organizations, academic institutions to examine for the techniques to use the tools for measuring and evaluating sustainability movement.

Over the past the world's energy consumption has doubled and it is estimated that onethird of the global warming gas emission comes from industry (Tonelli, Flavio, Evans, \& Taticchi., 2013). Thus, for the sustainability of the factories, and consequently of the whole environment, it becomes of outmost importance to increase the efficiency in energy waste in industries. (Stefano Gagliardo, Marina Monti, Terkaj, Marco Sacco, \& Salamone., 2014)

\footnotetext{
| ${ }^{1}$ Sustainability and Reliability of Infrastructure Program, Energy and Building Research Center, Kuwait Institute for Scientific Research
} 
In addition, in the cement industry the sustainable manufacturing has become an indispensable concept . Cement, which is the main component of concrete, considered, as is the most, consumed material after water and this industry revealed one of the as most controversial industries due to its significant environmental impacts. Due to the high level of consumption, the cement industry consider is one of the main industries affecting the built environment. (Fard, And, \& Chini, 2016). Cement is an crucial industrial product for economic development, nevertheless its production is exceptionally energy-intensive and indications to extreme pollution (Uwasu, Hara, \& Yabar, 2014).

The cement industry has regarded as one of the most energy intensive consumers amongst industries in the world (Aranda Usón, López-Sabirón, Ferreira, \& Llera Sastresa, 2013). Furthermore, cement factories are categorized as an intensive consumer of natural raw materials and fossil fuels, and has remarked as emitters of pollutants (Ali, Saidur, \& Hossain, 2011; Dao, Langella, \& Carbo, 2011). Globally, the cement firms are under concentrated pressure to condense the environmental impacts of their operations and products. Consequently, it is significant to establish and move toward sustainable manufacturing in this industry(Amrina, Ramadhani, \& Vilsi, 2016).

The sustainable manufacturing movements offers numerous commercial and business opportunities to members of the cement industry. Nevertheless, these opportunities carry substantial challenges and barriers. It is consequently essential to understand and address the main challenges and, barriers associated with implementing new sustainable cement manufacturing practices in order to succeed them and accelerate the expansion of sustainable manufacturing production and process. This paper is part of ongoing research aimed to identify and assess the extent of the utilization of efficient practice in the process of cement production in Kuwait and in turn produce new practice guidelines. Thus, the paper intends to address the challenge and barriers the sustainable manufacturing supposed to be suitable to the cement industry from the perspectives of the stakeholders.

\section{Methodology}

A qualitative research approach was applied in order to address the research objective. The qualitative approach entailed a comprehensive review of existing literature in order to compile a holistic overview of existing efficient sustainable cement and concrete production methods (Ali et al., 2011, Castañón et al., 2015). This paper is part of ongoing research aimed to identify and assess the extent of the utilization of efficient practice in the process of cement production in Kuwait and in turn produce new practice guidelines. Thus, the paper intends to address the challenge and barriers the sustainable manufacturing supposed to be suitable to the cement industry from the perspectives of the stakeholders. The information collected during this phase of the research formed the basis of the questions for the interviews asked to the cement factory stakeholders during the quantitative phase of the research. This allowed the researcher to address the barriers and challenges toward the sustainable cement factory from perspectives of the cement stakeholders. Moreover, critical analysis of the available literature particularly the studies on critical success barriers in the field. 


\section{Results and Discussion}

\subsection{Sampling \& Data}

A convenient and purposive sampling technique was used in this case, thereby giving the flexibility to choose the most appropriate sample. Meanwhile one of the aims of the study was to to address the challenge and barriers the sustainable manufacturing supposed to be suitable to the cement industry from the perspectives of the stakeholders in cement industry. Table 1 demonstrates the profile of the interviewees.

Table 1: Respondents Profile

\begin{tabular}{|l|l|l|}
\hline Managerial position & Years of experiences & Academic qualification \\
\hline Top management. & Between 21 to 25 years & Bachelor's degree \\
\hline Middle management. & More than 25 years. & Bachelor's degree. \\
\hline Middle management. & Between 16 to 20 & Bachelor's degree. \\
\hline Top management. & Between 21 to 25 years & Bachelor's degree \\
\hline Top management. & More than 25 years. & Bachelor's degree. \\
\hline Top management. & Between 5 to 10 years. & Master degree \\
\hline
\end{tabular}

As it can be seen from the data in Table 1 that, the experience range of the interviewees was from 6 to more than 25 years experiences in cement industry. Such experience range will help in gaining unbiased and reliable information. One of the interviewer has a master degree as academic qualification and the rest of the interviewers had bachelor's degree. The results indicated that the majority of the respondents are in in top managerial position in their factory and two of them worked as middle managerial position. The similar interview guide was employed in all the interviews. Nevertheless, the technique the questions were questioned was experienced as the interviews progressed.

\section{Analysis and Discussion}

The analysis of the interviews was carried out after all the interviews have been transcribed, analyzed and categorised to have meaningful and justified results. The main barriers and challenges toward sustainable cement factories identified by the interviews practitioners are listed below,

- Inadequate regulation support

- Lack of environmental awareness by the industry, political decision makers, and clients

- Lack of awareness on clients about sustainable building/construction

- Lack of a well-developed waste recycling market

- Infrastructure challenge for cement factory site location

- Lack of adequate road maintenance

- Lack of government interests in sustainable development.

- Challenges with the introduction of new technologies in factory

- Public and stakeholder acceptance

- Limited demand by clients for sustainable practices and product 
- Lack of appropriate local regulation to support the concept of sustainability

- Lack of incentives

- Lack of experts and professional knowledge of the concept.

- Lack of support to adopt concept of using recycle materials by government agency

- Improper waste disposal areas.

- Formal governmental documentation cycles.

- Lack of interests from government agencies.

- Complications in altering work practices of employees

- Lack of enforcement of construction and waste management policies and plans

- road maintenance and repair issue in factory site location

- Maintenance: High variability across locations

- Road deterioration due to lack of maintenance at factory location

- lack a sewage system at factory site location

- Sewage trucks purposely disposes the waste on roads

- Formal governmental documentation cycles and EPA authentications.

- Lack of concern by the Government regarding the industrial area.

- Poorly maintained roads, and poor infrastructure of the area.

- Lack of specialized agencies with experience in sustainable practices.

- Safety on the roads becomes an issue as the roads are poorly maintained.

- Poor monitoring and evaluation systems

- Shortage of local environmental regulations

The answer to this question highlights that the identification of the factors seems to be very much influenced by the respondents' experience and their background on cement industry. Respondents perception on the barriers and challenges highlighted toward moving to sustainable cement factory related to multiple teams and organizational structure as,

One of the research questions as highlighted above is to identify barriers in the implementation of sustainable cement factories Configuration Management process. It essential to identify and understand the barriers and challenges from the stakeholders perspectives which affect the efficiency of a process implementation in most efficient and effective way.

The data was collected through a semi-structured interviews on main barriers and challenges toward sustainable cement factories. Interviews were conducted to further investigate the subject and highlight barriers which the practitioners are facing main barriers and challenges toward sustainable cement factories. After detail analysis of the data, a list of thirteen factors were finalized on the basis of data received from source of data semi-structured interview. Details of the extracted obstacles to barriers and challenges toward sustainable cement factories,

From the list factor above can see thus barriers can be categories in the following category: social, economic and technical barriers. Several recommendation can be drawn in order to overcome the barriers toward the implementation . For example: Increase level of awareness about the important of sustainable movement through the industry, set a local guidance and rule to accelerate the movement. Incentives by the government, improving knowledge through the introduction of an educational program in this sector 
would lead to more experienced consumers who demand more efficient construction projects from the companies with which they work, thus promoting sustainable practices. Support by the through educational institutions would be favorable for promote improvement of the awareness and knowledge of sustainable-construction practice among future construction professionals(Alsanad, 2015).

\section{Conclusion}

Industrial is a main factor for the affluence of countries and an vital foundation of revolution and improvement. To ensure the competitiveness of manufacturing industry, factories have always needed to adapt to new challenges and trends, resulting in several changes of manufacturing paradigms over the last two centuries. Due to that, cement industry is one of the main industry have to improve the current production and move toward the sustainability. The factory of the future therefore responds to the identified challenges by addressing all three dimensions of sustainability, moving from today's rather economical focus towards ecological and social strategies. To achieve sustainability have to understand and reflect market perception through the concept. The cement industry is one of the most provocative industries due to its substantial environmental impacts. Additionally, this industry is an demanding consumer of energy, raw materials, high pollutant and fuels emitting industry. Annually nearby, 3.6 billion tons of cement is produced worldwide. Cement manufacturing is an energy intensive industrial process; besides the cement industry is one of the highest $\mathrm{CO}_{2}$ producing industrial sectors.

The sustainable manufacturing movements offers numerous commercial and business opportunities to members of the cement industry. Nevertheless, these opportunities carry substantial challenges and barriers. It is consequently essential to understand and address the main challenges and barriers associated with implementing new sustainable cement manufacturing practices in order to succeed them and accelerate the expansion of sustainable manufacturing production and process. This paper is part of ongoing research aimed to identify and assess the extent of the utilization of efficient practice in the process of cement production in Kuwait and in turn produce new practice guidelines. This study is part of ongoing research aimed to identify and assess the extent of the utilization of efficient practice in the process of cement production in Kuwait and in turn produce new practice guidelines. Thus, the paper intended to understand and identify list of barriers challenges toward sustainable cement factories. The results indicated a list of thirteen barriers factors from perspectives of cement industry stakeholders, which can be categories as social, economic and technical barriers factors. Several recommendation can be drawn in order to overcome the challenges, such as : set policies and incentives to promote SC increase public awareness toward the concept of sustainability, government support, set rule and legislation, improve the current cement factories practices and develop sustainable model and guideline for cement industry stokehole's

Further research will be conduct in order to validate and evaluate the list of perceived of barriers been highlighted from cement industry stakeholders and develop sustainable cement manufacturing. 


\section{References}

Ali, M. B., Saidur, R., \& Hossain, M. S. (2011). A review on emission analysis in cement industries. Renewable and Sustainable Energy Reviens, 15(5), 2252-2261. https://doi.org/10.1016/j.rser.2011.02.014

Alsanad, S. (2015). Awareness, Drivers, Actions, and Barriers of Sustainable Construction in Kuwait. In Procedia Engineering (Vol. 118). https://doi.org/10.1016/j.proeng.2015.08.538

Amrina, E., Ramadhani, C., \& Vilsi, A. L. (2016). A Fuzzy Multi Criteria Approach for Sustainable Manufacturing Evaluation in Cement Industry. Procedia CIRP, 40, 619-624. https://doi.org/10.1016/J.PROCIR.2016.01.144

Aranda Usón, A., López-Sabirón, A. M., Ferreira, G., \& Llera Sastresa, E. (2013). Uses of alternative fuels and raw materials in the cement industry as sustainable waste management options. Renewable and Sustainable Energy Reviews, 23, 242-260. https://doi.org/10.1016/J.RSER.2013.02.024

Arbačiauskas, V.Staniškis, J. (2009). Sustainability performance indicators for industrial enterprise management. Environmental Research, Engineering and Management, 48(2), 42-50.

Dao, V., Langella, I., \& Carbo, J. (2011). From green to sustainability: Information Technology and an integrated sustainability framework. The Journal of Strategic Information Systems, 20(1), 63-79.

Fard, M. M., And, C. J. K., \& Chini, A. R. (2016). Decision-making for sustainable location of a cement plant in the state of Florida. International Journal of Sustainable Engineering, 9, 76-92.

Stefano Gagliardo, F. G., Marina Monti, G. P., Terkaj, W., Marco Sacco, M. G., \& Salamone., F. (2014). An Ontology-based Framework for Sustainable Factories, 12(2), 198-207.

Tonelli, Flavio, Evans, S., \& Taticchi., P. (2013). Industrial sustainability: challenges, perspectives, actions. Journal of Business Innovation and Research, 7(2), 143-163.

Uwasu, M., Hara, K., \& Yabar, H. (2014). World cement production and environmental implications. Environmental Development, 10, 36-47. https://doi.org/10.1016/j.envdev.2014.02.005 